\title{
Exploring the complexity of domestication: a response to Rowley-Conwy and Zeder
}

Allowen Evin1,2, Linus Girdland Flink3,4,5, Ben Krause-Kyora6, Cheryl Makarewicz7, Sönke Hartz8, Stefan Schreiber6,9, Claus von Carnap-Bornheim7,8,10, Nicole von WurmbSchwark11, Almut Nebel6, Greger Larson3 \& Keith Dobney1

1 Department of Archaeology, University of Aberdeen, Aberdeen AB24 3UF, Scotland, UK. 2 MNHN-CNRS, UMR7209, 75005 Paris, France.

3 Durham Evolution and Ancient DNA, Department of Archaeology, Durham University, DH1 3LE Durham, UK.

4 School of Biological and Biomedical Sciences, Durham University, DH1 3LE Durham , UK. 5 Department of Palaeontology, Natural History Museum, SW7 5BD London, UK. 6 Institute of Clinical Molecular Biology, Christian-Albrechts-University, 24105 Kiel, Germany.

7 Institute of Pre- and Protohistoric Archaeology, Christian- Albrechts-University, 24105 Kiel, Germany.

8 Archäologisches Landesmuseum, Stiftung Schleswig-Holsteinische Landesmuseen Schloss Gottorf, 24837 Schleswig, Germany.

9 Clinic for Internal Medicine I, University Hospital Schleswig-Holstein, 24105 Kiel, Germany. 10 Center for Baltic and Scandinavian Archaeology, Stiftung Schleswig-Holsteinische Landesmuseen Schloss Gottorf, 24837 Schleswig, Germany.

11 Institute of Legal Medicine, Christian-Albrechts-University, 24105 Kiel, Germany.

\section{Introduction}

In their critique of our paper (Krause-Kyora et al 2013), Rowley-Conwy and Zeder focus on two primary issues. Firstly, they discuss issues associated with the terminology and definitions of animal domestication. Secondly, they question the techniques we employed to explore it. While we completely agree with their points related to terminology, we feel they have misunderstood both the principals and application of shape analyses using geometric morphometrics, and that this misunderstanding undermines their criticism. Having said that, and though our differences are easily overstated, our respective interpretations of the data presented in Krause-Kyora et al (2013) overlap significantly.

\section{Problems of concepts and terminology in domestication studies}

We completely agree with Rowley-Conwy and Zeder that domestication is neither a simple nor instantaneous process, and that the traditional terminology used in studies of domestication often precludes an appreciation for the biological process (Larson and Burger 2013; Dobney and Larson 2006). Numerous authors have previously described multiple pathways to animal domestication (e.g. Zeder et al. 2006; Zeder 2012; Vigne 2011) and there is general agreement that the process is complex and that its identification in the archaeological record is often problematic. Identifying wild and domestic forms of Sus scrofa in zooarchaeological assemblages is especially challenging since wild boar have a panEurasian (Old World) distribution.

The lack of specific terminology to describe different steps along domestication trajectories has clouded efforts to study, appreciate and communicate intermediate stages and status calls. In addition to 'wild' and 'domestic', concepts such as 'proto-domestication', 'predomestication', and 'semi-domestication' have been used to describe early steps or 
intermediate status in the process of animal domestication. In addition, because domestication occurs at the population level, identifying the status of individuals along the domestication trajectory is problematic.

Although zooarchaeologists have traditionally used size as a tool to distinguish wild and domestic forms of Sus scrofa (and other domesticates), several authors have emphasised the "inadequacy of using size alone" (e.g. Albarella et. al. 2006). Despite these reservations, the dichotomous framework in which small bones are considered domestic and large ones wild boar is frequently employed.

From a biological perspective, an animal that does not show all the characteristics of either a wild or domestic individual cannot strictly be considered one or the other, and many individuals fall into an uncertain middle ground based upon genetic, phenotypic, physiologic and behavioural characteristics. In Krause-Kyora et al (2013), we admit that our terminology was not as clear as it could have been, and that the use of words such as 'possess' led academics and the media to misinterpret or overly state our conclusions. For the record, we sought only to present evidence that several large Sus scrofa specimens (that would have been identified as 'wild' on the basis of size alone) also possessed a series of phenotypic and genetic traits that revealed definitive elements associated with a domestic ancestry. Since continuous gene-flow between wild and domestic populations probably played a significant role during early pig domestication and its human-mediated dispersal history (Larson \& Burger, 2013; Marshall, Dobney, Denham, \& Capriles, 2014), we feel it is more interesting to explore the ramifications of this mixed ancestry than to assign one of two dichotomous status calls.

We would also like to emphasise that any attempt to explore and assess the complexity of domestication using new approaches should not be interpreted as an attack against traditional, well-established techniques (or the "experienced archaeologists" - RowleyConwy and Zeder, p: 6, who practice them). Instead, we feel that adding to the tool kit available to zooarchaeologists presents more opportunities to explore our understanding of one of the most important bio-cultural transitions in human history.

\section{Analyses of molar size and shape}

In their criticisms of the methodology we used to explore shape analyses, Rowley-Conwy and Zeder comment on two of our previously published papers (Evin et al. 2013; Evin et al. 2014), both of which explored the morphometric differences between modern wild and domestic pigs. In general, they suggest that in those papers we dismissed traditional biometrics.

We disagree with this claim. Instead of replacing more standard approaches, our aim is to establish the limits of traditional morphometrics (Evin et al 2013; Evin et al. 2014) and expand the ability of morphological datasets to capture and study complex cranial and dental remains using geometric morphometrics (GMM). GMM is becoming a powerful tool for studying prehistoric animal domestication, commensalism and geographic dispersal. The methods have already been employed on a range of species such as pigs (Cucchi, Fujita, and Dobney 2009; Cucchi et al. 2011; Krause-kyora et al. 2013; Ottoni et al. 2013; Evin et al. 2013; Evin et al. 2014; Larson, Cucchi et al. 2007, Evin et al. in press), horse (Seetah, Cucchi, Dobney, \& Barker, 2014), house mouse (Thomas Cucchi et al., 2013; Valenzuela-Lamas, 
Baylac, Cucchi, \& Vigne, 2011) and common voles (Martinkova et al. 2013; Cucchi et al. in press).

GMM techniques possess numerous advantages, the principal one being an ability to study the geometry of an object (Rohlf \& Marcus, 1993). Using GMM, we have already established that molar shape is more accurate than molar size when distinguishing between modern wild and domestic Sus scrofa (Evin et al. 2013). This conclusion was based upon a comparison of the same set of specimens based on their size (measured using traditional metrical values of maximum tooth length and width), centroid size (a normalized metric value commonly used in GMM) and shape. We demonstrated that only 77.9-87.5\% of the specimens could be identified correctly (as wild or domestic) using maximum tooth length alone, while the results of a shape analysis correctly identified the status calls of $92.0-93.0 \%$ of the same specimens. Because decades of research have also produced large datasets of traditional metrics that only explore size variation (and because GMM is not yet routinely applied by archaeologists), we developed more statistically controlled and objective sets of criteria (including error risk assessments) to help identifying Sus remains based on traditional (linear) size measurements (Evin et al. 2014).

Interestingly, some of the Mesolithic specimens from the sites of Bloksbjerg and Sludegaard depicted in Figure 2 of Rowley-Conwy and Zeder's reply (which they interpret as wild boar) have relatively small molars. The size values of individuals from these two sites overlap with specimens from the Neolithic (interpreted as domestic pig), suggesting that these Mesolithic specimens may also have ancestry not wholly derived from Scandinavian wild boar (see below).

Rowley-Conwy and Zeder also criticised our use of modern wild boar from a wide geographic range as an interpretative baseline, suggesting that the variation across a large geographic area could explain the low proportion of specimens correctly identified on the basis of their size alone. It is important to note that the analyses of size and shape were made on the identical set of specimens, and that shape results were always more accurate than size for identifying the status of the specimen, independent of their provenance. Rowley-Conwy and Zeder also wrongly compared frequency values that correspond to different things. One percentage value was the proportion of correctly re-identified specimens based on our full datasets, and the other value was the percentage of archaeological specimens identified as domestic pigs. A direct comparison of these values is inappropriate. Used correctly, GMM is a powerful tool that can reveal greater resolution when assessing phenotypic changes linked with domestication and, as such, is likely to become a standard tool in zooarchaeology.

\section{Why specimen E24 from Grube-Rosenhof (Ertebølle culture) is not a wild boar:}

Krause-Kyora et al. (2013) assessed the status of LBK and Ertebølle suids from Northern Germany using three approaches (where possible) on the same specimens. These included coat colour expression identified using sequences of the $M C 1 R$ gene, a phylogeographic interpretation using analyses of mtDNA variation, and molar size and shape using both traditional and geometric morphometrics.

\section{Coat colour}

Though numerous MC1R alleles have been identified in Sus scrofa, wild boar possess only synonymous substitutions (that produce the same protein coding for camouflage coats), while domestic pigs possess several different non-synonymous mutations responsible for the 
varied coats found in domestic stocks (Fang, Larson, Ribeiro, Li, \& Andersson, 2009). In a recent study of coat colour amongst free-ranging wild boar at a breeding station, Koutsogiannouli et al. (2010) identified hybrid individuals that possessed both a wild and a domestic allele. Because the E24 specimen is homozygous (possessing two copies of the $\mathrm{E}^{\mathrm{P}}$ allele) it is unlikely to have been a first generation hybrid between a European wild boar and a domestic pig since there is a strong selection against domestic alleles in wild populations (Fang et al 2009). These data suggest that this specimen had likely been recently living in a domestic context, even if a proportion of its ancestry derived from wild boar incorporated into domestic stocks.

\section{Phylogeography}

The mitochondrial haplotype Y1, carried by the E24 specimen, has never been observed either in Mesolithic (assumed pre-domestic) nor modern European wild boar (Larson et al. 2005; Larson, Albarella, et al. 2007; Ottoni et al. 2013; Evin et al. 2014). Ancient DNA studies strongly suggest that this haplotype was introduced to Europe from the Near-East during the Neolithic transition (Krause-kyora et al., 2013; Larson, Albarella, et al., 2007; Ottoni et al., 2013). The haplotype Y1 was subsequently replaced in Europe by at least $3900 \mathrm{cal}$. BC (Larson, Albarella, et al., 2007) by local European haplotypes (probably through a process of extensive admixture with local wild boar). Again, the presence of this mitochondrial signature suggests that E24 derived at least in part from domestic stocks.

\section{Molar size and shape}

We compared the size and shape of molar E24 with our published (Krause-Kyora et al. 2013; Evin et al. 2013; see above) modern German wild and European domestic Sus scrofa dataset. Using size, E24 is indeed large and possesses values close to the average size of modern wild boar from central Europe. From a shape perspective, however, the GMM results demonstrated that E24 was more similar to modern domestic pigs. Because modern first generation hybrids between wild boar and domestic pigs possess molar sizes more similar to the domestic variants and certainly smaller than wild boar (Fig. 1, Evin et al. in press), the fact that E24 is large suggests, if it was a hybrid, it was not a first generation cross.

Taken together, both genetic and shape data clearly support our conclusion that E24 acquired a significant portion of its ancestry from domestic pigs. Only its large size contradicts this assumption. If this animal was a hybrid, it remains difficult to say either what proportion of its ancestry derived from wild or domestic stock, or when hybridisation actually took place. Several authors have recently highlighted the importance of continuous and multi-directional gene flow during the domestication (and dispersal) of pigs and other mammal domesticates (Larson \& Burger, 2013; Marshall et al., 2014). It is therefore no surprise that some zooarchaeological specimens possess a complex suite of phenotypic traits associated with both wild and domestic populations. Specimen E24 is one such specimen, underscoring the necessity to move beyond mutually exclusive status calls.

\section{Conclusion}

Zooarchaeologists have wrestled with questions related to identifying and defining domestic animals for decades (Zeder, Emshwiller, Smith, and Bradley 2006). Although we share (and agree with) the concerns articulated by Rowley-Conwy and Zeder relating to the problems associated with terminology to define the complex trajectories of the domestication process, the recent evidence for long-term gene flow between wild and domestic populations highlights the increasing lack of satisfaction of working within a framework that only makes 
use solely of dichotomous, mutually exclusive terminology. Such a framework continues to restrict our ability to fully understand and unravel the more intricate and continued interplay that exists between the cultural and biological aspects of domestication.

We did not intend to suggest in Krause-Kyora et al 2013 that later Mesolithic communities kept and reared domestic pigs. Instead, we presented evidence that one of the large Sus scrofa specimens (E24) found in a clear Erterbølle context at the site of Grube-Rosenhof possessed multiple characteristics associated with a domestic ancestry, and that its status raises intriguing questions about the nature of interaction between farmers and huntergatherers and between early Holocene European wild boar and (introduced) Neolithic domestic pigs.

Lastly, we maintain that some of the specimens from prehistoric Northern Germany (KrauseKyora et al 2013) represent not only the first animals with clear evidence of a domestic ancestry definitively identified from a Mesolithic site in continental northern Europe, but also direct (proxy) evidence for the earliest presence of domestic animals in the region.

\section{Acknowledgements:}

We once again thank the many institutions and individuals that provided sample material and access to collections, especially the curators of the Museum für Haustierkunde, Halle; Museum für Naturkunde, Berlin; Zoologische Staatssammlung, Munich; Muséum National d'Histoire Naturelle, Paris; The American Museum of Natural History, New-York. This work was supported by NERC (grant number NE/F003382/1).

Fig. 1: Log transformed centroid size of the lower M3 for modern German wild boar, European domestic breeds and first generation hybrids.

\section{References}

Albarella, U., Dobney, K. and Rowley-Conwy, P. 2006. The domestication of the Pig (Sus scrofa): New Challenges and Approaches. In University of California Press (Ed.), Documenting domestication : new genetic and archaeological paradigms (Vol. 44, pp. 209-227). Berkley.

Cucchi, T., Barnett, R., Martínková, N., Renaud, S., Renvoisé, E., Evin, A., Sheridan, A., Mainland,I. , Wickham-Jones, C., Tougard, C., Quéré, J.-P., Pascal, M., Pascal, M., Heckel, G., O'Higgins, P., Searle, J. B. and Dobney, K. M. (in press). The changing pace of insular life: 5000 years of microevolution in the Orkney vole (Microtus arvalis orcadensis). Evolution, 1-47. doi:10.1111/evo.12476.

Cucchi, T., Fujita, M. and Dobney, K. 2009. New insights into pig taxonomy, domestication and human dispersal in Island South East Asia: molar shape analysis of Sus remains from Niah Caves, Sarawak. International Journal of Osteoarchaeology, 19(4), 508-530.

Cucchi, T., Hulme-Beaman, a., Yuan, J. and Dobney, K. 2011. Early Neolithic pig domestication at Jiahu, Henan Province, China: clues from molar shape analyses using geometric morphometric approaches. Journal of Archaeological Science, 38(1), 11-22. 
Cucchi, T., Kovács, Z. E., Berthon, R., Orth, A., Bonhomme, F., Evin, A., Siahsarvie, R., Darvish, J., Bakhshaliyev, V. and Marro, C. 2013. On the trail of Neolithic mice and men towards Transcaucasia: zooarchaeological clues from Nakhchivan (Azerbaijan). Biological Journal of the Linnean Society, 108(4), 917-928.

Dobney, K. and Larson, G. 2006. Genetics and animal domestication: new windows on an elusive process. Journal of Zoology, 269(2), 261-271.

Evin, A., Cucchi, T., Cardini, A., Strand Vidarsdottir, U., Larson, G. and Dobney, K. 2013. The long and winding road: identifying pig domestication through molar size and shape. Journal of Archaeological Science, 40(1), 735-743.

Evin, A., Cucchi, T., Escarguel, G., Owen, J., Larson, G., Strand Vidarsdottir, U. and Dobney, K. 2014. Using traditional biometrical data to distinguish West Palearctic wild boar and domestic pigs in the archaeological record: New methods and standards. Journal of Archaeological Science, 43, 1-8.

Evin, A., Girdland Flink, L., Bălășescu, A., Popovici, D., Andreescu, R., Bailey, D., Mirea, P., Lazar, C., Boroneant, A., Bonsall, C., Strand Vidarsdottir, U., Brehard, S., Tresset, A., Cucchi, T., Larson, G. and Dobney, K. In press. Unravelling the complexity of domestication: A case study using morphometrics and ancient DNA analyses of archaeological pigs from Romania. Philosophical Transaction of the Royal Society $B$.

Fang, M., Larson, G., Ribeiro, H. S., Li, N. and Andersson, L. 2009. Contrasting mode of evolution at a coat color locus in wild and domestic pigs. PLoS Genetics, 5(1), e1000341.

Koutsogiannouli, E. A., Moutou, K. A., Sarafidou, T., Stamatis, C. and Mamuris, Z. 2010. Detection of hybrids between wild boars (Sus scrofa scrofa) and domestic pigs (Sus scrofa f. domestica) in Greece, using the PCR-RFLP method on melanocortin-1 receptor (MC1R) mutations. Mammalian Biology - Zeitschrift Fur Saugetierkunde, 75(1), 69-73.

Krause-kyora, B., Makarewicz, C., Evin, A., Flink, L. G. and Dobney, K. 2013. Use of domesticated pigs by Mesolithic hunter-gatherers in Northwest Europe, 1-7.

Larson, G., Albarella, U., Dobney, K., Rowley-Conwy, P., Schibler, J., Tresset, A., Vigne, J.-D., Edwards, C. J., Schlumbaum, A., Dinu, A., Bălășescu, A., Doman, G., Tagliacozzo, A., Manaseryan, N., Miracle, P., Van Wijngaarden-Bakker, L., Masseti, M., Bradley, D. G. and Cooper, A. 2007. Ancient DNA, pig domestication, and the spread of the Neolithic into Europe. Proceedings of the National Academy of Sciences of the United States of America, 104(39), 15276-81.

Larson, G. and Burger, J. 2013. A population genetics view of animal domestication. Trends in Genetics : TIG, 29(4), 197-205.

Larson, G., Cucchi, T., Fujita, M., Matisoo-smith, E., Robins, J., Anderson, A., et al. 2007. Phylogeny and ancient DNA of Sus provides insights into neolithic expansion in Island Southeast Asia and Oceania Proceedings of the National Academy of Sciences ,104 (12) 4834-4839. 
Marshall, F. B., Dobney, K., Denham, T. and Capriles, J. M. 2014. Evaluating the roles of directed breeding and gene flow in animal domestication. Proceedings of the National Academy of Sciences, 111(17), 6153-6158.

Martinkova, N., Barnett, R., Cucchi, T., Higham, T., Brace, S., Ho, S. Y. W., et al. 2013. Divergent evolutionary processes associated with colonization of offshore islands. Evolution, 22, 5205-5220.

Ottoni, C., Flink, L. G., Evin, A., Geörg, C., De Cupere, B., Van Neer, W., et al. 2013. Pig domestication and human-mediated dispersal in western Eurasia revealed through ancient DNA and geometric morphometrics. Molecular Biology and Evolution, 30(4), 824-32.

Rohlf, J. F. and Marcus, L. F. 1993. A revolution in morphometrics. Trends in Ecology \& Evolution, 8(4), 129-132.

Seetah, K., Cucchi, T., Dobney, K. and Barker, G. 2014. A geometric morphometric reevaluation of the use of dental form to explore differences in horse (Equus caballus) populations and its potential zooarchaeological application. Journal of Archaeological Science, 41, 904-910.

Valenzuela-Lamas, S., Baylac, M., Cucchi, T. and Vigne, J. D. 2011. House mouse dispersal in Iron Age Spain : a geometric morphometrics appraisal. Biological Journal of the Linnean Society, 102, 483-497.

Vigne, J.-D. 2011. The origins of animal domestication and husbandry : A major change in the history of humanity and the biosphere. Comptes Rendus - Biologies, 334(3), 171-181.

Zeder, M. A. 2012. Pathways to Animal Domestication. In R. L. B. et al. P. P. Gepts, T.R. Famula (Ed.), Biodiversity in Agriculture: Domestication, Evolution, and Sustainability (pp. 227259). Cambridge University Press.

Zeder, M. A., Emshwiller, E., Smith, B. D. and Bradley, D. G. 2006. Documenting domestication: the intersection of genetics and archaeology. Trends in Genetics : TIG, 22(3), 139-55. 


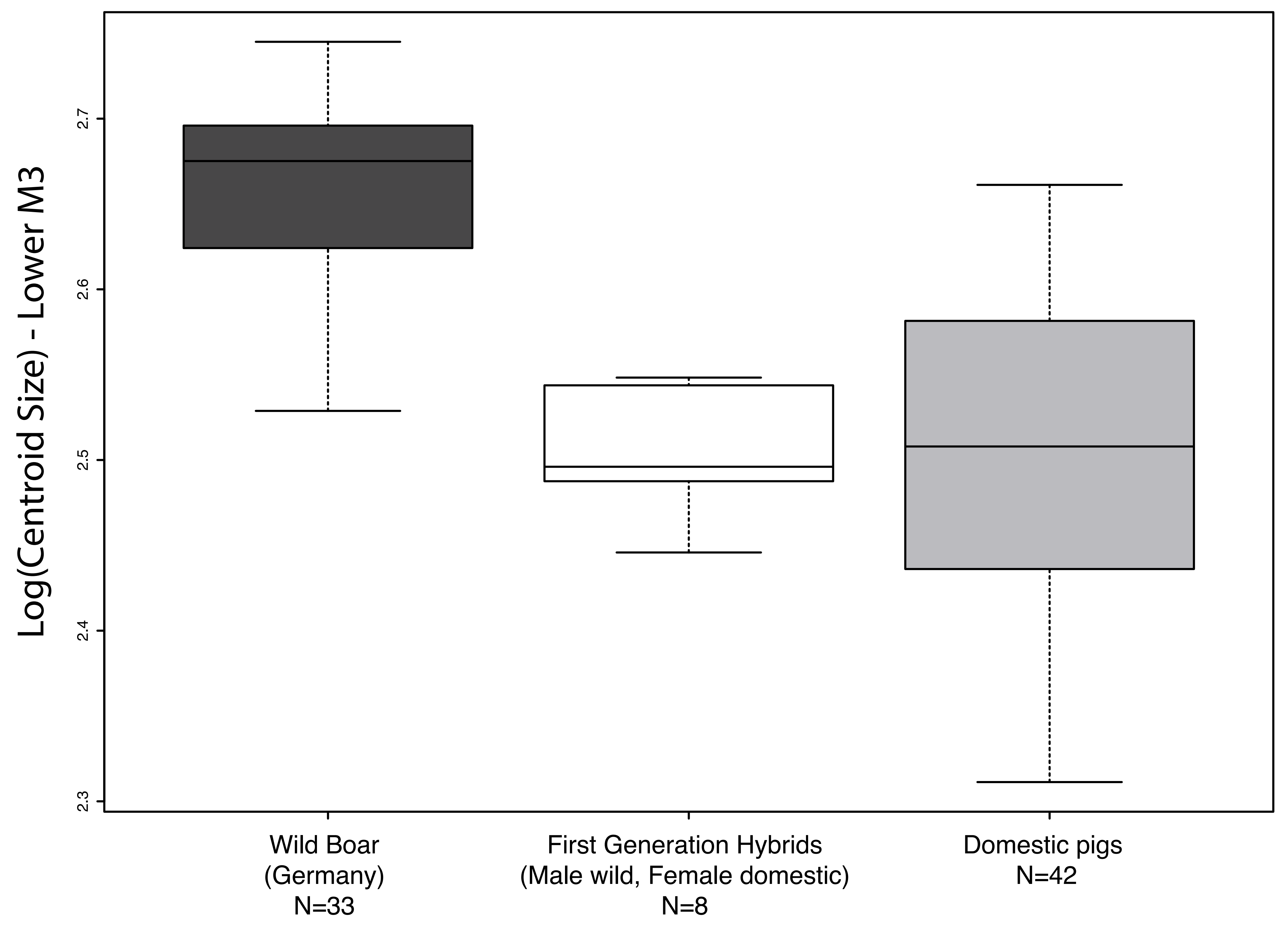

